Subscriber access provided by The Bodleian Libraries of The University of Oxford

\title{
Article
}

\section{Dynamics of silver nanoparticles in aqueous solution in the presence of metal ions}

Kamonwad Ngamchuea, Christopher Batchelor-McAuley, Stanislav V. Sokolov, and Richard G Compton

Anal. Chem., Just Accepted Manuscript • DOI: 10.1021/acs.analchem.7b01470 • Publication Date (Web): 08 Sep 2017

Downloaded from http://pubs.acs.org on September 8, 2017

\section{Just Accepted}

"Just Accepted" manuscripts have been peer-reviewed and accepted for publication. They are posted online prior to technical editing, formatting for publication and author proofing. The American Chemical Society provides "Just Accepted" as a free service to the research community to expedite the dissemination of scientific material as soon as possible after acceptance. "Just Accepted" manuscripts appear in full in PDF format accompanied by an HTML abstract. "Just Accepted" manuscripts have been fully peer reviewed, but should not be considered the official version of record. They are accessible to all readers and citable by the Digital Object Identifier (DOI®). "Just Accepted" is an optional service offered to authors. Therefore, the "Just Accepted" Web site may not include all articles that will be published in the journal. After a manuscript is technically edited and formatted, it will be removed from the "Just Accepted" Web site and published as an ASAP article. Note that technical editing may introduce minor changes to the manuscript text and/or graphics which could affect content, and all legal disclaimers and ethical guidelines that apply to the journal pertain. ACS cannot be held responsible for errors or consequences arising from the use of information contained in these "Just Accepted" manuscripts. 


\title{
Dynamics of silver nanoparticles in aqueous solution in the presence of metal ions
}

Kamonwad Ngamchuea, Christopher Batchelor-McAuley, Stanislav V. Sokolov, Richard G. Compton*

* corresponding author: Richard G. Compton, Department of Chemistry, Physical \& Theoretical Chemistry Laboratory, University of Oxford, South Parks Road, Oxford, OX1 3QZ, United Kingdom

Email: richard.compton@chem.ox.ac.uk. Tel: +44(0)1865275957 Fax: +44(0)1865275410

\begin{abstract}
Using a combined UV-Vis, DLS and electrochemical approach, this work experimentally studies the physical origin of the observed colormetric sensitivity of aqueous silver nanoparticles towards divalent metal ions. In the presence of $\mathrm{Pb}^{2+}, \mathrm{AgNPs}$ are show to reversibly form agglomerates (the time scale of the reverse de-agglomeration process is of the order of hours). This agglomeration is shown to be induced by complex formation between $\mathrm{Pb}^{2+}$ and citrate groups localized on the AgNPs, reducing surface charges (zeta-potential) and hence electrostatic repulsion between the AgNPs. Other divalent metal ions including $\mathrm{Ca}^{2+}$, $\mathrm{Cd}^{2+}, \mathrm{Zn}^{2+}, \mathrm{Ni}^{2+}, \mathrm{Co}^{2+}$ and $\mathrm{Sn}^{2+}$ are also studied and the resulting sizes of the AgNPs clusters and the extents of the UV-vis spectrum red-shift in $\lambda_{\max }$ have a strong positive correlation with the metal-ligand (citrate) complex formation constant $\left(\mathrm{K}_{\mathrm{f}}\right)$. This work thus serves as a guide for the selection of capping agents on the basis of $\mathrm{K}_{\mathrm{f}}$ and demonstrates the correlation between sizes and spectrophotometric as well as electrochemical responses of the AgNPs clusters. Importantly, we give further physical insights into the size-dependent properties of AgNPs, and emphasize the difference between theoretical and experimental values of extinction coefficients, where the latter is affected by the angle-dependent scattering intensities and the measurement technique used.
\end{abstract}




\section{Introduction}

A plethora of examples of the use of silver nanoparticles for colorimetric and spectrophotometric sensing of metal ions are present in the literature. The most significant variant between these reports is the use of different capping agents. Recent examples include gallic acid, ${ }^{1}$ iminodiacetic acid, ${ }^{2}$ ILP, ${ }^{3}$ tyrosine, ${ }^{4} \mathrm{MTT}^{5}$ and biothiols. ${ }^{6-8}$ Generally, a semiempirical approach has been taken towards the discovery of new capping agents with the aim of improving the sensitivity and selectivity of the procedure. Nevertheless, we note that most of the ligands previously studied contain either a carboxylate and/or a thiol group, and that in many cases high selectivity towards a specific metal, most often lead (II), is demonstrated. However, many such articles limit themselves to reporting the observed behaviour at the expense of providing insight into the solution phase dynamics of the nanoparticle solution and the probable physico-chemical cause of the altered response.

Silver nanoparticles possess interesting optical properties as their surface plasmon resonance give rise to a strong absorption band in the visible range. The extinction coefficients of the silver nanoparticles $\left(\varepsilon_{\text {perNP }}=10^{8}-10^{11} \mathrm{M}^{-1} \mathrm{~cm}^{-1}\right)^{9}$ are several orders of magnitude higher than other types of chromophores, ${ }^{10,11}$ making them 'ideal' for colorimetric applications. The colours and absorption spectra of the silver nanoparticles are dependent on their size, shape and the relative permittivity of the local environment. The different absorption spectra of the silver nanoparticles (AgNPs) of different sizes has been well-explored both theoretically and experimentally. ${ }^{12,13}$ The analysis of the absorbance and the extinction coefficients is usually done on the basis of Beer-Lambert law and concentrations are generally described in terms of the particles concentration. ${ }^{9}$ However, it will be demonstrated herein for particles of different sizes that by considering the concentration of silver atoms rather than that of silver nanoparticles, insightful and analytically useful information can be obtained. This includes, for example, the discrepancy between the theoretically predicted and experimental UV-Vis spectra, the size-dependent contributions of absorption and scattering in particular.

In sensing applications, the alteration in absorption spectra in response to the change in the relative permittivity becomes of relevant interest. The relative permittivity can change with solvent, the chemical species adsorbed on the surface and the interaction between the particles. ${ }^{14}$ It is the latter two factors that draw our attention to the use of AgNPs as a sensor for chemical species. In this work, aqueous citrate-capped AgNPs and lead (II) are used as a 
model system to study the interactions between AgNPs capped with small ligands and the metal ions. Citrate and lead (II) are chosen based on the hypothesis deduced from literature review that lead (II) would give rise to spectrophotometric changes of the AgNPs capped with carboxylate-containing ligands. We note that the behaviour of silver nanoparticles in other solvents may differ from that found herein. The investigations into the solution phase dynamics of the AgNPs/lead(II) systems are performed using a range of techniques: UV-Vis spectrophotometry, dynamic light scattering (DLS) and electrochemical nano-impact experiments. ${ }^{15,16}$ The absorption spectra reveal the responses of plasmon resonances and are used to study the reversibility of the interactions. DLS and nano-impacts ${ }^{15}$ are employed to monitor the in-situ sizes of the particles upon the addition of lead (II) solutions. The in-situ techniques allow the monitoring of the size of nanoparticles or nanoparticle clusters in solution-phase, as opposed to transmission electron microscopy (TEM) where the complication of particle agglomeration/aggregation may arise upon solvent evaporation during sample preparation. Based on these techniques, analytical approaches are also developed for the determination of lead (II). Other metal (II) ions are investigated along with the selectivity of the analysis.

\section{Experimental}

\section{Chemical reagents and instrumentation}

All reagents were used as received without further purification: sodium citrate (Aldrich, 99\%), lead (II) nitrate (BDH, 99.5\%), calcium nitrate tetrahydrate (BDH, 99.0\%), cadmium (II) nitrate tetrahydrate (Aldrich, 99.999\%), zinc nitrate hexahydrate (Aldrich, 98\%), nickel (II) nitrate hexahydrate (Aldrich, 99.999\%), cobalt (II) nitrate hexahydrate (Sigma-Aldrich, $>98 \%$ ), tin (II) chloride (Aldrich, >99.99\%), potassium chloride (Sigma-Aldrich, >99.0\%). All solutions were prepared using deionized water (Millipore) with a resistivity of $18.2 \mathrm{M} \Omega \mathrm{cm}\left(25^{\circ} \mathrm{C}\right)$.

The UV-Vis measurements were performed with a Shimadzu UV-1800 spectrophotometer in disposable cuvettes (Eppendorf UVette, Sigma-Aldrich) using a $10 \mathrm{~mm}$ optical path length. Electrochemical experiments were performed with a $\mu$ Autolab Type III potentiostat (Utrecht) using a standard three electrode setup employing the fabricated carbon fiber microwire $(7 \mu \mathrm{m}$ 
diameter, Goodfellow UK) working electrode, ${ }^{17}$ saturated calomel (BASi) reference electrode and a platinum mesh counter electrode.

\section{Synthesis and characterization of citrate-AgNPs}

The spherical citrate-AgNPs of $9 \mathrm{~nm}$ diameter and the triangular prismatic citrate-AgNPs were synthesized in our research group. ${ }^{18-20}$ The spherical citrate-AgNPs of $30 \mathrm{~nm}, 50 \mathrm{~nm}$ and $100 \mathrm{~nm}$ diameters were obtained from Nanocomposix, USA. All of the citrate-AgNPs were characterized using transmission electron microscopy (TEM, $300 \mathrm{kV}$ JEOL 3000F microscope) and dynamic light scattering (DLS, ZEN3600 Nano-ZS Zetasizer).

\section{Procedures for the analytical detection of $\mathrm{Pb}^{2+}$}

First, the UV-Vis spectra of $29 \mathrm{nM}$ of $9 \mathrm{~nm}$ citrate-AgNPs were recorded in the range of wavelength of 250-800 nm upon the addition of different concentrations of lead nitrate solutions $(0-1,000 \mu \mathrm{M})$. The position of the wavelength at maximum absorbance $\left(\lambda_{\max }\right)$ and/or the absorbance at $250 \mathrm{~nm}\left(\mathrm{~A}_{250}\right)$ are determined and plotted against concentration of $\mathrm{Pb}^{2+}$ to construct calibration curves. The concentration of $\mathrm{Pb}^{2+}$ in the unknown solution can then be determined by the addition of citrate-AgNPs (yielding the same final concentration of $29 \mathrm{nM}$ ) followed by the UV-Vis measurement. The values of $\lambda_{\max }$ and/or $\mathrm{A}_{250}$ measured are then compared with the calibration curves to yield the concentration of $\mathrm{Pb}^{2+}$.

\section{Investigations of the interactions between citrate-AgNPs and divalent metal ions}

Sizing of citrate-AgNPs/Pb ${ }^{2+}$ clusters. The sizes of the citrate-AgNPs in the presence of different concentrations of $\mathrm{Pb}^{2+}$ was determined by DLS and the nano-impacts technique. ${ }^{15}$ DLS measurements were performed using $59 \mathrm{nM}$ of $9 \mathrm{~nm}$ or $7.6 \mathrm{pM}$ of $50 \mathrm{~nm}$ AgNPs to react with $0,250,500,750$ and $1,000 \mu \mathrm{M}$ of $\mathrm{Pb}^{2+}$. Nano-impact experiments were performed in 10 $\mathrm{mM} \mathrm{KCl}$ electrolytes using $7.6 \mathrm{pM}$ of $50 \mathrm{~nm}$ citrate- $\mathrm{AgNPs}$ in the absence and presence of $1,000 \mu \mathrm{M}$ of $\mathrm{Pb}^{2+}$.

Reversibility. The reversibility of the reaction between citrate-AgNPs and $\mathrm{Pb}^{2+}$ was studied by dilution of the mixture of $59 \mathrm{nM} 9 \mathrm{~nm}$ citrate-AgNPs and $1,000 \mu \mathrm{M} \mathrm{Pb}^{2+}$ with deionized water to the dilution factors of 1.5, 2.0 and 2.5. Their UV-Vis spectra are recorded every one minute for the first $7 \mathrm{~min}, 6$ hours and 30 hours after the dilutions. The resulting spectra are 
then compared with those expected for the fresh mixtures of $\mathrm{AgNPs}$ and $\mathrm{Pb}^{2+}$ of equivalent concentrations to that after the dilutions.

Comparison between different divalent metal ions $\left(\mathrm{M}^{2+}\right)$. In addition to $\mathrm{Pb}^{2+}$, other different metal divalent ions including $\mathrm{Ca}^{2+}, \mathrm{Cd}^{2+}, \mathrm{Zn}^{2+}, \mathrm{Ni}^{2+}, \mathrm{Co}^{2+}$ and $\mathrm{Sn}^{2+}$ were investigated. UVVis spectra $(250-800 \mathrm{~nm})$ of the mixtures of $7.6 \mathrm{pM} 50 \mathrm{~nm}$ citrate-AgNPs and $500 \mu \mathrm{M}$ of each metal ion solution were recorded and compared.

\section{Results and Discussion}

Given that the main observations for the interaction of silver nanoparticles with metal ions is the change in the colour of the suspension, the article starts by considering the nanoparticle UV-Vis spectra and how the data is best interpreted and analyzed (Section 3.1). Following this, the UV-Vis spectra of the citrate-AgNPs is reported with the addition of different concentrations of lead (II) solutions (Section 3.2). In order to provide insights into the solution phase nanoparticle dynamics in the presence of metal ions, the results from both DLS and the nano-impact technique are presented in Section 3.3. The reversibility of the colour change is investigated in Section 3.4. Finally, Section 3.5 provides an explanation for the observed selectivity of the colour change towards lead (II) ions.

\section{UV-Vis studies of citrate-AgNPs and the interpretation of the resulting spectra}

The citrate-AgNPs were characterized using TEM and DLS. Their average sizes are given in Table 1, and the size distributions provided in Figure S1 (SI). Figure 1a presents the UV-Vis spectra of the AgNPs samples $(\lambda=250-1,000 \mathrm{~nm})$. For the smaller quasi-spherical particles a clear plasmon peak is observable at $\sim 400 \mathrm{~nm}$. The large spherical $(100 \mathrm{~nm})$ and prismatic particles exhibit shifted absorption maxima. Unlike for molecular species, the extinction coefficient contains contributions from both absorption and scattering. Under conditions where the particle is small compared to the wavelength of light used then under the quasistatic approximation the scattering coefficients, $\varepsilon_{\text {abs }}$ and $\varepsilon_{\text {scatt }}$ can be described as: ${ }^{14}$

$$
\begin{aligned}
& \varepsilon_{\mathrm{abs}}=4 \pi N k r^{3} \operatorname{Im}\left[\frac{\epsilon_{\mathrm{in}}-\epsilon_{\text {out }}}{\epsilon_{\mathrm{in}}+2 \epsilon_{\text {out }}}\right] \\
& \varepsilon_{\text {scatt }}=\frac{8}{3} \pi N k^{4} r^{6}\left|\frac{\epsilon_{\text {in }}-\epsilon_{\text {out }}}{\epsilon_{\text {in }}+2 \epsilon_{\text {out }}}\right|^{2}
\end{aligned}
$$


where $\varepsilon_{\text {abs }}$ and $\varepsilon_{\text {scatt }}$ are absorption and scattering coefficients respectively, and the sum of $\varepsilon_{\text {abs }}$ and $\varepsilon_{\text {scatt }}$ gives $\varepsilon_{\text {ext }}\left(\varepsilon_{\text {ext }}=\varepsilon_{\text {abs }}+\varepsilon_{\text {scatt }}\right) . r$ is the radius of the particles, $k$ is the wavevector in the medium and $N$ is the atomic number density.

First, we note that the scattering is strongly anisotropic, with the fraction of forward scattering increasing with the size of the particle. Second, in a UV-Vis measurement light is made in the forward direction and over a finite range of angles. Consequently, relating theory to the measured UV-Vis spectra, specifically predicting the scattering contribution is not a straight forward task. But we highlight that the absorption coefficient is proportional to the nanoparticle volume, hence for small particles one would anticipate the magnitude of the UV-Vis spectra to relate to the solution phase silver atom concentration. The UV-Vis data presented in Figure 1a has been normalized against the concentration of silver atoms in the suspensions and not the number of particles. For all but the largest particles, the adsorption maxima are very comparable in magnitude. This is the case even though the number of nanoparticles in the four suspensions differs by over two orders of magnitude.

To emphasize this point further, Figure $1 \mathrm{~b}$ displays the Beer-Lambert plots of absorbance at $\lambda_{\max }$ against concentration of silver atoms, with the inlay showing the equivalent plot as a function of silver nanoparticles concentration. The Beer-Lambert plots vs. silver nanoparticles are markedly different for the nanoparticles of different sizes. The resulting values of $\varepsilon_{\text {ext }}$ per NP are provided in Table 1 . The values of $\varepsilon_{\text {ext }}$ calculated using the concentrations of silver atoms are in the range of $15,300 \pm 300$ (Ag atom) $\mathrm{M}^{-1} \mathrm{~cm}^{-1}$, refer to Table 1 . The slightly different values of $\varepsilon_{\text {ext }}$ possibly reflect the errors in the concentrations of silver used in the synthesis. Only the $100 \mathrm{~nm}$ AgNPs have $\varepsilon_{\text {ext }}$ an order of magnitude lower than the smaller particles.

Given that Evanoff et al. ${ }^{12}$ reports that for silver nanoparticles scattering and absorption contribute equally to the extinction coefficient when particles are ca. $52 \mathrm{~nm}$ in size, it is of interest to ask why the adsorption maxima for the reported $50 \mathrm{~nm}$ particles exhibit a very comparable measured extinction coefficient to the much smaller $9 \mathrm{~nm}$ particles (on a per atom basis). Again we emphasize that the measured spectra are highly dependent on the technique used. In the case of UV-Vis which is a widely-used method among analytical chemists, the detector is placed in front of the sample or at the scattering angle $(\theta)$ of $\sim 0^{\circ}$. For small particles the scattering intensities are maximum for forward $\left(\theta=0^{\circ}\right)$ and backward $(\theta=$ $\left.180^{\circ}\right)$ scattering, and minimum at the perpendicular angle $\left(\theta=90^{\circ}\right) .^{21}$ The light scattered in 
the other directions except for $\theta=0^{\circ}$ is not detected by the detector, and hence increases the magnitude of 'absorbance' measured by the UV-Vis.

In contrast, as the particle size becomes comparable to the wavelength of light such as the $100 \mathrm{~nm}$ AgNPs studied, scattering now gives the highest intensity in the forward direction $(\theta$ $\left.=0^{\circ}\right){ }^{21}$ More scattered light reaches the detector and decreases the value of 'absorbance' measured by the UV-Vis. The extinction coefficient from the UV-Vis measurement is thus significantly lower than anticipated for the smaller size particles. This result emphasizes the difference between experimental and theoretical values of extinction coefficients. Nonetheless, from our work it is suggested that for AgNPs not larger than $50 \mathrm{~nm}$ in diameter, the UV-Vis maximum absorbance can be analyzed using the Beer-Lambert law using the value of $\varepsilon_{\text {ext }}$ per silver atom of $15,300 \pm 300\left(\mathrm{Ag}\right.$ atom) $\mathrm{M}^{-1} \mathrm{~cm}^{-1}$. The value of $\varepsilon_{\text {ext }}$ per silver nanoparticle can also be approximated, see S2 (SI).
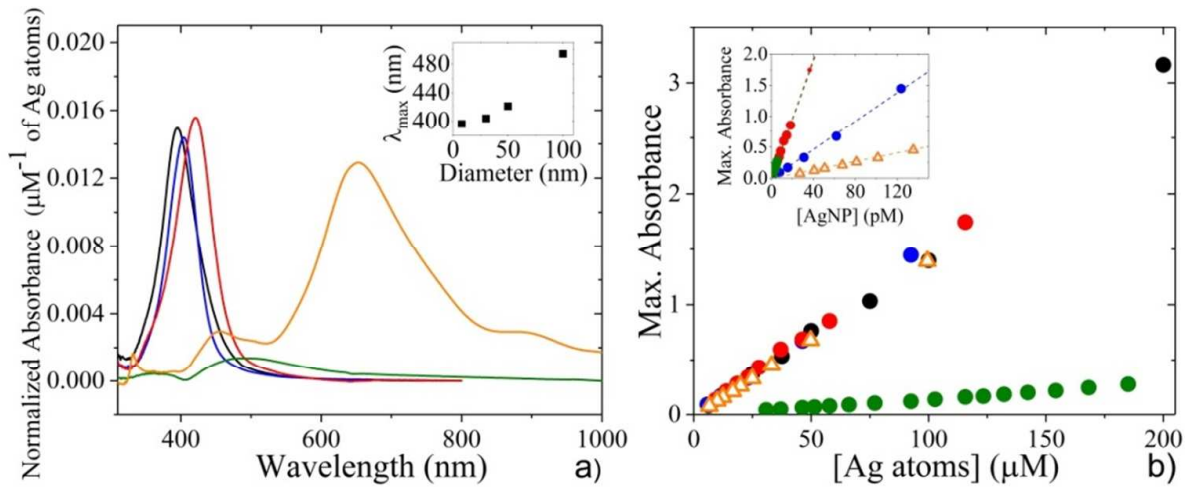

Figure 1: a) UV-Visible spectra of citrate-AgNPs of different sizes normalized with the concentrations of silver atoms; (Inlay) the wavelengths at maximum absorbance $\left(\lambda_{\max }\right)$ as a function of the AgNPs diameters. b) Beer-Lambert plots of absorbance at $\lambda_{\max }$ as a function of silver atoms concentrations and (Inlay) absorbance at $\lambda_{\max }$ as a function of silver nanoparticles concentrations for citrate-AgNPs of different shapes and sizes. Black, blue, red and green designate spherical citrate-AgNPs of $9 \mathrm{~nm}, 30 \mathrm{~nm}, 50 \mathrm{~nm}$ and $100 \mathrm{~nm}$ in diameter respectively; orange designates triangular-prism citrate-AgNPs of $33 \mathrm{~nm}$ triangular height and $7 \mathrm{~nm}$ prism thickness.

Table 1: Sizes of citrate-AgNPs from TEM and DLS measurements, and the extinction coefficients $(\varepsilon)$ calculated on the basis of Beer-Lambert law using silver nanoparticle or silver atom concentrations.

\begin{tabular}{ccccc}
\hline$*$ & $\begin{array}{c}\text { TEM } \\
\text { diameter } \\
(\mathbf{n m})\end{array}$ & $\begin{array}{c}\text { DLS z- } \\
\text { average } \\
(\mathbf{n m})\end{array}$ & $\begin{array}{c}\mathbf{\varepsilon} \text { per AgNP } \\
\left(\mathbf{1 0}^{\mathbf{1 1}} \mathbf{M}^{\mathbf{- 1}}\right. \\
\left.\mathbf{c m}^{-\mathbf{1}}\right)\end{array}$ & $\begin{array}{c}\mathbf{\varepsilon} \text { per Ag atom } \\
\left(\mathbf{M}^{\mathbf{- 1}} \mathbf{c m}^{\mathbf{- 1}}\right)\end{array}$ \\
\hline$[\mathbf{1}]$ & $9 \pm 2$ & $18 \pm 12$ & $3.34 \pm 0.03$ & $15,460 \pm 220$ \\
{$[\mathbf{2}]$} & $29 \pm 4$ & $39 \pm 9$ & $634 \pm 2$ & $15,520 \pm 150$ \\
{$[\mathbf{3}]$} & $47 \pm 6$ & $60 \pm 11$ & $2,580 \pm 4$ & $14,995 \pm 95$ \\
{$[\mathbf{4}]$} & $103 \pm 9$ & $111 \pm 11$ & $2,586 \pm 2$ & $1,445 \pm 35$ \\
{$[\mathbf{5}]$} & $h: 33 \pm 9^{\dagger}$ & $25 \pm 15$ & $344 \pm 1$ & $13,980 \pm 190$ \\
& $l: 7 \pm 1^{19}$ & & &
\end{tabular}

* [1] spherical (made in house), ${ }^{18}$ [2] spherical (Nanocomposix, Nanoxact $30 \mathrm{~nm}$ ), [3] spherical (Nanocomposix, Nanoxact $50 \mathrm{~nm}$ ), [4] spherical (Nanocomposix, Nanoxact $100 \mathrm{~nm}$ ), [5] triangular prisms (made in house) ${ }^{19}$

$\dagger \quad h$ and $l$ are the height of the triangular surface and the thickness of the prism respectively. 


\section{$\mathrm{UV}$-Vis responses of the citrate- $\mathrm{AgNP} / \mathrm{Pb}^{2+}$ solutions}

In this section, the optical properties and the UV-Vis responses of the citrate-AgNPs are investigated upon additions of $\mathrm{Pb}^{2+}$ solutions. The absorption spectra are recorded for the mixtures of citrate-AgNPs (58 nM of $9 \mathrm{~nm}$ AgNPs or $7.6 \mathrm{pM}$ of $50 \mathrm{~nm} \mathrm{AgNPs})$ and $\mathrm{Pb}^{2+}(0-$ $1,000 \mu \mathrm{M})$. The resulting UV-Vis spectra are presented in Figure $2 \mathrm{a}$ and $2 \mathrm{~d}$ for $9 \mathrm{~nm}$ and 50 $\mathrm{nm}$ AgNPs respectively. Two distinct features are observed to change with the concentrations of $\mathrm{Pb}^{2+}$ added: the absorbance at $\lambda=250 \mathrm{~nm}\left(\mathrm{~A}_{250}\right)$ and the positions of $\lambda_{\max }$. $\mathrm{A}_{250}$ increases with $\mathrm{Pb}^{2+}$ concentrations, while $\lambda_{\max }$ shifts to longer wavelengths, both changes of which are plotted against the concentrations of $\mathrm{Pb}^{2+}$ in Figure $2 \mathrm{~b}$ and $2 \mathrm{e}$ for $9 \mathrm{~nm}$ and $50 \mathrm{~nm}$ AgNPs respectively.

In the case of $9 \mathrm{~nm} \mathrm{AgNPs}$ in the presence of $200 \mu \mathrm{M}$ and $300 \mu \mathrm{M} \mathrm{Pb}^{2+}$, the spectra in the region of $350-600 \mathrm{~nm}$ split into two peaks, which are labelled Peak I and Peak II. The magnitude of the maximum absorbance, or the sum of absorbance at Peak I and Peak II if there are two separate peaks, remains constant with $\mathrm{Pb}^{2+}$ concentrations, indicating the relation of the spectra in this region to the amount of silver, see Figure $2 \mathrm{c}$ and $2 \mathrm{f}$ for $9 \mathrm{~nm}$ and $50 \mathrm{~nm}$ AgNPs respectively. Note that the slightly higher maximum absorbance at high $\mathrm{Pb}^{2+}$ concentrations, especially for the $50 \mathrm{~nm}$ AgNPs, is caused by the interference of the absorbance due to the citrate- $\mathrm{Pb}^{2+}$ complex $\left(\mathrm{A}_{250}\right)$ which will be discussed in Section 3.5.

Further results on the effects of concentrations of citrate-AgNPs, and electrolytes towards the detection of lead ions are provided in section S3 (SI). The change in colour is presented in Figure S4 (SI). The lowest limits of detection were obtained when $29 \mathrm{nM}$ of $9 \mathrm{~nm}$ citrateAgNPs were used (Figures S2a and S2b), yielding the limits of detection $\left(3 \mathrm{~S}_{\mathrm{B}} / \mathrm{m}\right)$ of $35 \mu \mathrm{M}$ and $18 \mu \mathrm{M}$ based on $\lambda_{\max }$ and $\mathrm{A}_{250}$ respectively. From the limits of detection determined, it is suggested that the developed method may be suitable for the determination of $\mathrm{Pb}^{2+}$ in industrial wastewater where the concentration of $\mathrm{Pb}^{2+}$ are in the range of $5-15 \mathrm{mg} / \mathrm{L}(24.1 \mu \mathrm{M}$ to $72.4 \mu \mathrm{M}){ }^{22}$

This shift in the UV-Vis response and the change in colour of the nanoparticle suspension in the presence of $\mathrm{Pb}^{2+}$ demonstrates that the AgNPs capped with carboxylate-containing ligands (citrate in this case) chemically interact. Having demonstrated that we can obtain analytically useful information from the interactions between citrate-AgNPs and $\mathrm{Pb}^{2+}$ as 
previously reported for other capping agents, ${ }^{1-8}$ next we investigate the cause of the changes in absorption spectra.
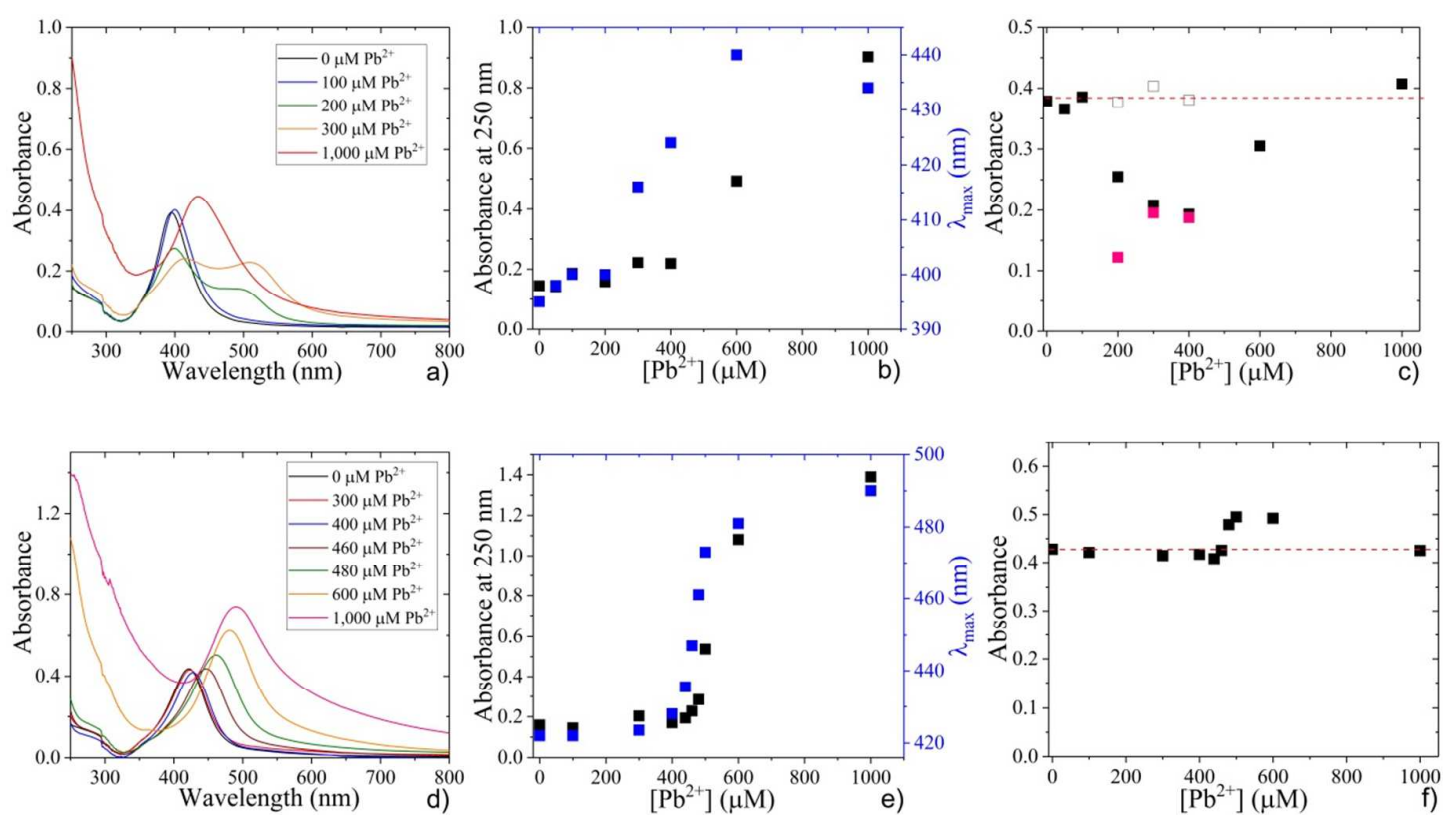

Figure 2: a) UV-Vis spectra, b) (black) absorbance at $250 \mathrm{~nm}$ and (blue) $\lambda_{\max }$ plotted against concentrations of $\mathrm{Pb}^{2+}$, and c) absorbance at (black squares) $\lambda_{\max }$ or Peak I if spectra split into two peaks, (pink squares) Peak II, (open squares) sum of absorbance at Peak I and Peak II of the mixtures of $58 \mathrm{nM} 9 \mathrm{~nm}$ citrate-AgNPs and 0-1,000 $\mu \mathrm{M}$ of $\mathrm{Pb}^{2+}$. d) UV-Vis spectra, e) (black) absorbance at $250 \mathrm{~nm}$ and (blue) $\lambda_{\max }$ plotted against concentrations of $\mathrm{Pb}^{2+}$ and f) absorbance at $\lambda_{\max }$ of the mixtures of $7.6 \mathrm{pM} 50 \mathrm{~nm}$ citrate-AgNPs and $0-1,000 \mu \mathrm{M}$ of $\mathrm{Pb}^{2+}$.

\section{Solution phase dynamics of the citrate- $\mathrm{AgNP} / \mathrm{Pb}^{2+}$ solutions - evidencing the formation of AgNPs clusters}

It is thought that the plasmon resonance of the particles and hence the resulting absorption spectra change according to three main factors: solvents, formation of AgNP clusters and adsorption of $\mathrm{Pb}^{2+}$ on the surface of the AgNPs. The only change made to the solvent is the addition of low concentrations of $\mathrm{Pb}^{2+}$ which is approximated from the resemblance of the $\mathrm{UV}-\mathrm{Vis}$ spectra of $\mathrm{Pb}^{2+}$ solution and pure water to cause a negligible effect on the relative permittivity of the medium. Consequently, in this section we focus on the possible formation of AgNP clusters in $\mathrm{Pb}^{2+}$ solutions. The sizes of the AgNPs in the presence of different concentrations of $\mathrm{Pb}^{2+}$ are determined using two in-situ techniques: dynamic light scattering and the electrochemical nano-impacts technique.

The hydrodynamic sizes of the AgNPs in the presence of $0,250,500$ and $1,000 \mu \mathrm{M} \mathrm{Pb}^{2+}$ from DLS measurements are summarized in Table 2. The average sizes of the particles become significantly larger in the presence of $\mathrm{Pb}^{2+}$, and the size increases with increasing 
$\mathrm{Pb}^{2+}$ concentration. These results thus indicate the formation of AgNP clusters induced by $\mathrm{Pb}^{2+}$.

Table 2: DLS sizes of the nanoparticles in the presence of different concentrations of $\mathrm{Pb}^{2+}$ in the absence of added electrolytes. Similar experiments were performed in the presence of $10 \mathrm{mM} \mathrm{KCl}$, the results of which are provided in Section S5 in the SI.

\begin{tabular}{ccc}
\hline $\begin{array}{c}\left.\mathbf{P b}^{2+}\right] \\
(\boldsymbol{\mu M})\end{array}$ & $\begin{array}{c}\text { AgNPs d = 8 nm } \\
\text { z-average (nm) }\end{array}$ & $\begin{array}{c}\text { AgNPs d = 50 nm } \\
\text { z-average }(\mathbf{n m})\end{array}$ \\
\hline 0 & $18 \pm 12$ & $52 \pm 2$ \\
250 & $125 \pm 33$ & $59 \pm 11$ \\
500 & $291 \pm 63$ & $157 \pm 12$ \\
750 & $457 \pm 103$ & $381 \pm 82$ \\
1000 & $639 \pm 157$ & $870 \pm 152$ \\
\hline
\end{tabular}

Nano-impact experiments are also performed to confirm the cluster formation of the NPs in the presence of $\mathrm{Pb}^{2+}$ and obtain further information about the nature of the clusters. The potential of $0.8 \mathrm{~V}$ vs SCE is applied at a carbon fiber working electrode and the currents monitored as a function of time. The electrochemical measurements are performed in $10 \mathrm{mM}$ $\mathrm{KCl}$ supporting electrolyte to provide sufficient screening of the positively charged $\mathrm{Ag}^{+}$ oxidation product, and hence ensure complete oxidation of the AgNPs. ${ }^{23}$ The examples of nano-impact spikes are given in Figure 3.

Figure 3a displays the typical sharp spikes of AgNPs, where each spike represents a AgNP being completely oxidized at the electrode, giving the charge transfer of $0.48 \pm 0.23 \mathrm{pC}$ in the duration of $18 \pm 5 \mathrm{~ms}$. These amounts of charge transfer correspond to the diameters of AgNPs of $45 \pm 8 \mathrm{~nm}$, in excellent agreement with the size from TEM measurements of $47 \pm 6$ $\mathrm{nm}$. The detailed analysis of nano-impact spikes are provided in Section S6 (SI).

In the presence of $1,000 \mu \mathrm{M} \mathrm{Pb}^{2+}$, the duration of spikes becomes significantly longer $(719 \pm$ $621 \mathrm{~ms}$ ) indicating the much larger sizes of the particles as longer times are required for the large particles to be fully oxidized, see Figure $3 \mathrm{~b}$. The charge transfer is determined to be 174 $\pm 173 \mathrm{pC}$, corresponding to $297 \pm 101 \mathrm{~nm}$ diameters assuming the clusters are spherical. Importantly, the detectable nano-impact spikes of the AgNPs clusters further demonstrates that the interacting forces between the clusters are relatively strong, and that if the formation of clusters is reversible, the disassembly of the clusters is much slower than the oxidation of AgNPs upon the impact on the electrode. ${ }^{24,25}$ Otherwise, only monomeric NPs would be detected. $^{26}$ 

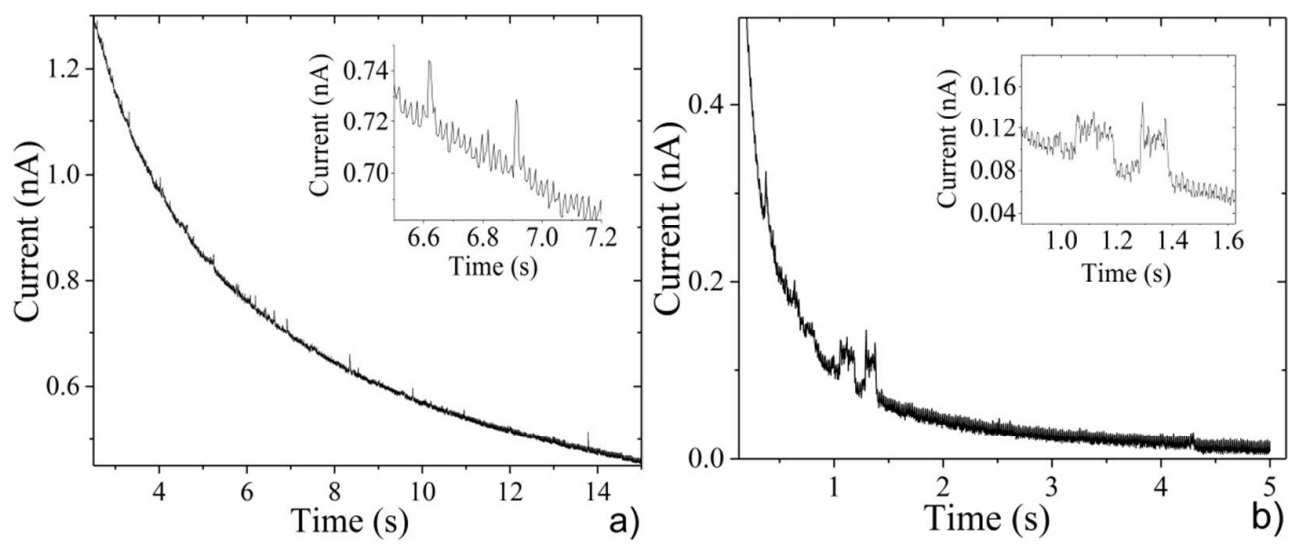

Figure 3: Chronoamperograms showing nano-impact spikes of a) $7.6 \mathrm{pM}$ of $50 \mathrm{~nm}$ AgNPs and b) $7.6 \mathrm{pM}$ of $50 \mathrm{~nm}$ AgNPs in the presence of $1,000 \mu \mathrm{M} \mathrm{Pb}^{2+}$ using $7 \mu \mathrm{m}$ carbon fiber working electrode, standard calomel reference electrode and platinum counter electrode, $E=0.8 \mathrm{~V}$ vs $\mathrm{SCE}, 10 \mathrm{mM} \mathrm{KCl}$ supporting electrolyte.

\section{Reversibility of the AgNPs cluster formation in $\mathrm{Pb}^{2+}$ solutions - Agglomeration vs. Aggregation}

The previous section has evidenced that the addition of $\mathrm{Pb}^{2+}$ to $\mathrm{AgNPs}$ suspension results in the formation of the AgNPs clusters. In this section, it is investigated whether this cluster formation is an agglomeration (reversible) or aggregation (irreversible) process. ${ }^{27}$ This was achieved by mixing $58 \mathrm{nM}$ of $9 \mathrm{~nm}$ AgNPs and $1,000 \mu \mathrm{M} \mathrm{Pb}^{2+}$. The mixture is then diluted with deionized water to the dilution factors of $1.5,2.0$ and 2.5 yielding $39 \mathrm{nM} \mathrm{AgNP} / 667 \mu \mathrm{M}$ $\mathrm{Pb}^{2+}, 29 \mathrm{nM} A g N P / 500 \mu \mathrm{M} \mathrm{Pb}^{2+}$ and $23 \mathrm{nM}$ AgNP/400 $\mu \mathrm{M} \mathrm{Pb}^{2+}$ respectively. The UV-Vis spectra of the diluted mixtures are recorded and compared with the mixtures prepared fresh to the equivalent concentrations of AgNPs and $\mathrm{Pb}^{2+}$. Figure 4 demonstrates the results for the dilution factors of 2.5 showing the shape of the UV-Vis spectra returning gradually to that expected for the $23 \mathrm{nM}$ AgNP/400 $\mu \mathrm{M} \mathrm{Pb}^{2+}$ mixtures. The time scale of the reverse process is determined based on the ratios between the absorbance at $405 \mathrm{~nm}$ to $517 \mathrm{~nm}$ to be of the order of hours. Further results are provided in Section S7 (SI).

From this result, it can thus be concluded that the interaction with $\mathrm{Pb}^{2+}$ leads to the reversible agglomeration of the AgNPs, with slow de-agglomeration process. The slow rate of the deagglomeration establishes credibility in the determination of metal ions based on the sizes of the nanoparticles clusters as it ensures that no cluster de-agglomerates in the timescale of the measurement. The reversibility of the agglomeration also suggests the possible re-use of the nanoparticles in analysis as there is no irreversible loss. However due to the reversibility of the agglomeration process, in the extreme cases where a separation process is required and 
the process takes a significant period of time, the measured responses may not truly reflect the concentrations of the metal ions in the samples, and caution should be exercised.

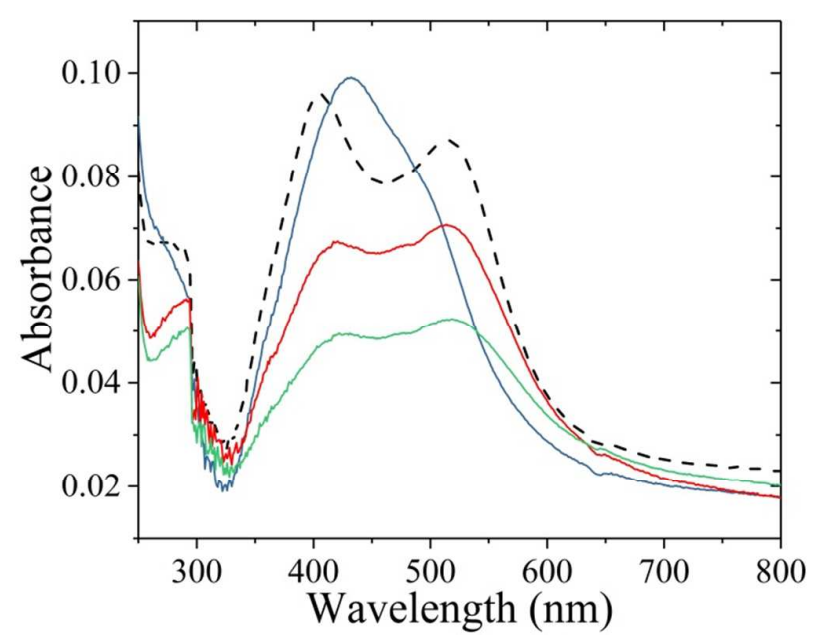

Figure 4: UV-Vis spectra of the mixtures of $23 \mathrm{nM} \mathrm{AgNP} / 400 \mu \mathrm{M} \mathrm{Pb}^{2+}$ yielding from the dilution of $58 \mathrm{nM}$ of $9 \mathrm{~nm} \mathrm{AgNPs}$ and $1,000 \mu \mathrm{M} \mathrm{Pb}^{2+}$ to the dilution factor of 2.5. Blue, red and green lines designate the spectra of the diluted mixtures $7 \mathrm{~min}$, $6 \mathrm{hr}$ and $30 \mathrm{hr}$ after dilution respectively. Black dashed line shows the spectrum of fresh $23 \mathrm{nM} \mathrm{AgNP} / 400 \mu \mathrm{M} \mathrm{Pb}^{2+}$ mixtures, i.e. not from dilution.

\section{Origins of the reversible agglomeration}

In this section, the physical origins of the agglomeration of citrate-AgNPs in the presence of $\mathrm{Pb}^{2+}$ are examined. Figure 5 compares the UV-Vis spectra of the mixtures of $\mathrm{Pb}^{2+}$ and citrate-AgNPs, with that of $\mathrm{Pb}^{2+}$ and the solution-phase citrate. The spectra display strong absorbance at $250 \mathrm{~nm}\left(\mathrm{~A}_{250}\right)$ which is absent prior to the mixing between $\mathrm{Pb}^{2+}$ and any form of citrate. This indicates complex formation between $\mathrm{Pb}^{2+}$ and citrates, both in solution-phase and as ligands bound to the surface of AgNPs. Citrate contains three carboxylate groups and likely binds to $\mathrm{Pb}^{2+}$ via the oxygen/carbonyls of the carboxylate groups. ${ }^{28} \mathrm{The} \mathrm{Pb}-\mathrm{O}^{29}$ and the $\mathrm{Pb}-\mathrm{OOC}$ interaction in ethylenediaminetetraacetic acid (EDTA) ${ }^{30}$ have been reported to display strong absorption in this short wavelength region.

Monolayer adsorption of citrate on gold nanoparticles is ca. $2.8 \times 10^{-10} \mathrm{~mol} \mathrm{~cm}^{-2}$, the number of which is also applicable to the silver surface as it has similar lattice spacings. ${ }^{31}$ For 15.1 $\mathrm{pM}$ of the commercial (Nanocomposix) $50 \mathrm{~nm}$ citrate-AgNPs, the suspension contains 625 $\mu \mathrm{M}$ citrate, $<1 \%$ of which is localized on the AgNPs while $>99 \%$ remains in the solution. For the mixtures of $15.1 \mathrm{pM} 50 \mathrm{~nm}$ citrate-AgNPs (containing $625 \mu \mathrm{M}$ citrate) and 1,000 $\mu \mathrm{M}$ $\mathrm{Pb}^{2+}$, the magnitude of $\mathrm{A}_{250}$ is significantly higher than that of the mixture of $\mathrm{Pb}^{2+}$ with the same concentration of citrate in solution. At the same time, the absorption spectrum in the 250-350 nm range of the $\mathrm{Pb}^{2+} /$ solution-phase citrate mixture only becomes comparable to that 
of $15.1 \mathrm{pM} 50 \mathrm{~nm}$ citrate-AgNPs (containing $625 \mu \mathrm{M}$ citrate) and $1,000 \mu \mathrm{M} \mathrm{Pb}^{2+}$ when the concentration of $\mathrm{Pb}^{2+}$ is increased to $2,000 \mu \mathrm{M}$. The higher amount of $\mathrm{Pb}^{2+}$ required to reach a comparable magnitude as that of the citrate-AgNPs of equivalent citrate concentration implies that the AgNPs act as the carriers of the citrate, localizing high concentrations of citrate on the surface. This likely facilitates the complex formation and hence improves the sensitivity of the detection of $\mathrm{Pb}^{2+}$.

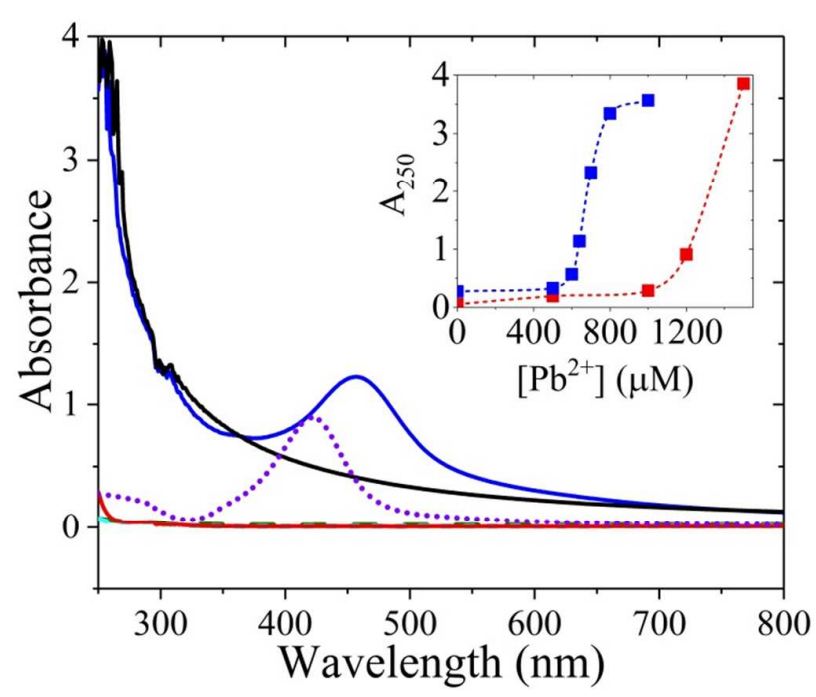

Figure 5: UV-Vis spectra of (Dashed, green) $625 \mu \mathrm{M}$ citrate; (Dashed, light blue) $1,000 \mu \mathrm{M} \mathrm{Pb}^{2+}$ (overlay on top of the dashed green line); (Dotted, purple) $15.1 \mathrm{pM} 50 \mathrm{~nm}$ citrate-AgNPs; (Red) $1,000 \mu \mathrm{M} \mathrm{Pb}^{2+}+625 \mu \mathrm{M}$ citrate; (Black) 2,000 $\mu \mathrm{M} \mathrm{Pb}^{2+}+625 \mu \mathrm{M}$ citrate; (Blue) $1,000 \mu \mathrm{M} \mathrm{Pb}^{2+}+15.1 \mathrm{pM} 50 \mathrm{~nm}$ citrate-AgNPs (containing $625 \mu \mathrm{M}$ citrate; $>99 \%$ in solution and the remaining localized on the nanoparticles). (Inlay) Calibration curves showing the absorbance at $250 \mathrm{~nm}\left(\mathrm{~A}_{250}\right)$ as a function $\mathrm{Pb}^{2+}$ concentration interacting with (Blue) $15.1 \mathrm{pM} 50 \mathrm{~nm}$ citrate-AgNPs (containing $625 \mu \mathrm{M}$ citrate) or (Red) $625 \mu \mathrm{M}$ citrate

The zeta potentials of the citrate-AgNPs are measured to be $-23.3 \pm 1.8 \mathrm{mV}$ and $-10.0 \pm 0.2$ $\mathrm{mV}$ in the absence and presence of $750 \mu \mathrm{M} \mathrm{Pb}^{2+}$ respectively, see Section S8 (SI) for raw data. The decrease in the surface charges reduces the electrostatic repulsion, and leads to the agglomeration of the AgNPs. The $\mathrm{Pb}^{2+}$ ion can also potentially act as a bridge between nanoparticles to form agglomerates. The modification made to the surface environment and the agglomeration of the NPs (decreasing particles separation) alter the plasmon resonance frequency, shifting the position of the absorption peak to longer wavelengths upon the binding of $\mathrm{Pb}^{2+}$.

In addition to $\mathrm{Pb}^{2+}$, the UV-Vis spectra and DLS measurements were performed for the mixtures of $7.6 \mathrm{pM}$ of $50 \mathrm{~nm}$ citrate-AgNPs and $500 \mu \mathrm{M}$ of different divalent cations $\left(\mathrm{Ca}^{2+}\right.$, $\mathrm{Cd}^{2+}, \mathrm{Zn}^{2+}, \mathrm{Ni}^{2+}, \mathrm{Co}^{2+}$ and $\left.\mathrm{Sn}^{2+}\right)$. Mono- and other multi-valent cations are not considered in 
this work to eliminate the complication arising from different ionic strengths. The resulting values of $A_{250}$ and $\Delta \lambda_{\max }$ are summarized in Table 3, together with the formation constants $\left(\mathrm{K}_{\mathrm{f}}\right)$ of the citrate- $\mathrm{M}^{2+}$ complexes. The raw spectra are given in Section S9 (SI).

The complex formation constant $\left(\mathrm{K}_{\mathrm{f}}\right)$ is defined as:

$$
\mathrm{M}^{2+}+\text { Citrate }^{3-} \stackrel{\mathrm{K}_{\mathrm{f}}}{\rightleftharpoons}[\mathrm{M}-\text { Citrate }]^{-}
$$

where $\mathrm{M}^{2+}$ and $[\mathrm{M}-\mathrm{Citrate}]^{-}$are divalent metal cations and the metal-citrate complex respectively. $\mathrm{K}_{\mathrm{f}}=[\mathrm{M}-\text { Citrate }]^{-} /\left[\mathrm{M}^{2+}\right]\left[\right.$ Citrate $\left.^{3-}\right]$.

As shown in Table 3, both the sizes of the particles and $\Delta \lambda_{\max }$ increase with $\mathrm{K}_{\mathrm{f}}$. At the same concentration, $\mathrm{M}^{2+}$ with higher $\mathrm{K}_{\mathrm{f}}$ values form higher concentrations of the $[\mathrm{M}-\mathrm{Citrate}]^{-}$ complex. Consequently, more significant change is likely made to the nanoparticle surface dielectric constant. At the same time, the complex formation between $\mathrm{M}^{2+}$ and citrate leads to the decrease in zeta-potential, and hence agglomeration. Both the localization of $\mathrm{Pb}^{2+}$ on the surface of AgNPs and the decrease in the particle separation may give rise to strong nearfield coupling, ${ }^{14}$ developing a large charge dipole across the gap between the particles and hence changing the frequency of the plasmon resonance.

Apart from the carboxylate-containing ligands (such as citrate), AgNPs localized with biothiols also show high selectivity towards $\mathrm{Pb}^{2+} \cdot{ }^{6-8}$ Crea et al. ${ }^{32}$ report that the complex formation between $\mathrm{Pb}^{2+}$ and biological S-donor ligands have the high $\log \left(\mathrm{K}_{\mathrm{f}}\right)$ values of greater than 10, and hence further support the inference that the selectivity in the metal ion detection by silver nanoparticles is governed by the magnitude of $\mathrm{K}_{\mathrm{f}}$ of metal-ligand binding.

Both $\mathrm{Pb}^{2+}$ and $\mathrm{Sn}^{2+}$ have high $\log \left(\mathrm{K}_{\mathrm{f}}\right)$ values for citrate complex formation and both show significant shifts in $\lambda_{\max }$ and form large agglomerates. However, $\Delta \lambda_{\max }$ of citrate-AgNPs in the presence of $\mathrm{Sn}^{2+}$ is smaller than that in $\mathrm{Pb}^{2+}$ solutions, suggesting that although $\mathrm{K}_{\mathrm{f}}$ is dominant, it may not be a sole factor. This is thought to be a result of the larger size of $\mathrm{Pb}^{2+}$ allowing the formation of complexes with higher coordination number. Nonetheless, the knowledge of $\mathrm{K}_{\mathrm{f}}$ dependence on the size of AgNPs clusters and the shift in plasmon resonance in $\mathrm{M}^{2+}$ solutions allows the bottom-up design of the nanoparticle sensors, and the selection of the capping ligands in particular. This work indicates that capping ligands can be chosen on the basis of complex formation constant with the target analytes. 
Table 3: Literature values of metal-citrate complex formation constants $\left(\mathrm{K}_{\mathrm{f}}\right)$; UV-Vis experimental values of absorbance at $250 \mathrm{~nm}\left(\mathrm{~A}_{250}\right)$ and $\Delta \lambda_{\max }$ for the mixtures of $7.6 \mathrm{pM} 50 \mathrm{~nm}$ citrate-AgNPs and $500 \mu \mathrm{M}$ of different $\mathrm{M}^{2+}$.

\begin{tabular}{|c|c|c|c|c|c|c|c|}
\hline \multirow{2}{*}{$\mathbf{M}^{2+}$} & \multicolumn{4}{|c|}{ Metal-citrate complex formation constant $\left(K_{f}\right)$} & \multirow{2}{*}{$\mathbf{A}_{\mathbf{2 5 0}}$} & \multirow{2}{*}{$\begin{array}{l}\Delta \lambda_{\max } \\
(\mathbf{n m})\end{array}$} & \multirow{2}{*}{$\begin{array}{c}\text { DLS } \\
\text { z-average (nm) }\end{array}$} \\
\hline & & $\log \left(K_{f}\right)$ & & average $\log \left(K_{f}\right)$ values & & & \\
\hline $\mathrm{Ca}^{2+}$ & $4.9^{33,34}$ & $3.15^{35}$ & $4.84^{36}$ & $4.30 \pm 0.99$ & 0.09 & 1 & 64 \\
\hline $\mathrm{Cd}^{2+}$ & $4.2^{37}$ & $3.98^{38}$ & & $4.09 \pm 0.16$ & 0.10 & 0 & 59 \\
\hline $\mathrm{Zn}^{2+}$ & $3.55^{39}$ & $4.85^{38}$ & $4.71^{40}$ & $4.37 \pm 0.71$ & 0.14 & 2 & 59 \\
\hline $\mathrm{Ni}^{2+}$ & $5.11^{38}$ & $4.47^{41}$ & $4.99^{42}$ & $4.86 \pm 0.34$ & 0.12 & 1 & 57 \\
\hline $\mathrm{Co}^{2+}$ & $4.83^{38}$ & $4.16^{43}$ & $4.41^{42}$ & $4.47 \pm 0.34$ & 0.16 & 1 & 60 \\
\hline $\mathbf{P b}^{2+}$ & $5.74^{44}$ & $6.5^{44}$ & & $6.12 \pm 0.54$ & 0.21 & 22.5 & 157 \\
\hline $\mathrm{Sn}^{2+}$ & $19.5^{45}$ & $10.3^{46}$ & & $14.90 \pm 4.60$ & 0.37 & 15 & 1,036 \\
\hline
\end{tabular}

\section{Conclusions}

We have examined the physical origins underlying the interactions between AgNPs capped with small ligands and the metal ions in aqueous solution (the extension of these result to other media and conditions warrants further investigation). The interactions which give rise to the changes in optical and spectrophotometric responses of the AgNPs are found to be due to the reversible agglomeration of the particles caused by the complex formation between the metal ions and the capping agents. The complex formation reduces the zeta-potential of the particles and hence leads to particle agglomeration. The sizes of the agglomerates and the shift in the plasmon resonance frequency are governed by the strength of the metal ioncapping agent complex. This work thus provides evidences and physical explanation to facilitate the choice of capping agent selection (based on $\mathrm{K}_{\mathrm{f}}$ ) for the detection of the species of interest. We have also shown that the analytical detection of metal ions, using lead (II) as an example, can be done on the basis of optical, spectrophotometric, dynamic light scattering or electrochemical nano-impact measurements of the AgNPs suspensions.

\section{Acknowledgements}

We thank Ms. Jessica Lee for the synthesis of silver nanoparticles. KN acknowledges funding from DPST scholarship, the Royal Thai government. This project is supported by the funding from the European Research Council under the European Union's Seventh Framework Programme (FP/2007-2013)/ERC Grant Agreement no. [320403].

\section{Supporting Information}


TEM images of citrate-AgNPs; calculations of $\varepsilon_{\text {ext }}$; UV-Vis spectra and change in colours of citrate-AgNPs upon the addition of $\mathrm{Pb}^{2+}$; effect of electrolytes; nano-impacts; reversibility of the agglomeration; zeta-potential of citrate-AgNPs in the absence and presence of $\mathrm{Pb}^{2+}$; binding of citrate-AgNPs to different divalent cations

\section{References}

(1) Yoosaf, K.; Ipe, B. I.; Suresh, C. H.; Thomas, K. G. J. Phys. Chem. C 2007, 111, 1283912847.

(2) Qi, L.; Shang, Y.; Wu, F. Microchim. Acta 2012, 178, 221-227.

(3) Vinod Kumar, V.; Anthony, S. P. Sens. Actuators, B 2014, 191, 31-36.

(4) Annadhasan, M.; Muthukumarasamyvel, T.; Sankar Babu, V. R.; Rajendiran, N. ACS Sustainable Chem. Eng. 2014, 2, 887-896.

(5) Noh, K. C.; Nam, Y. S.; Lee, H. J.; Lee, K. B. Analyst 2015, 140, 8209-8216.

(6) Anambiga, I. V.; Suganthan, V.; Arunai Nambi Raj, N.; Buvaneswari, G.; Sampath Kumar, T. S. IJSER 2013, 4, 710.

(7) Hu, L.; Hu, S.; Guo, L.; Tang, T.; Yang, M. Anal. Methods 2016, 8, 4903-4907.

(8) Chen, X.; Cheng, X.; Gooding, J. J. Analyst 2012, 137, 2338-2343.

(9) Paramelle, D.; Sadovoy, A.; Gorelik, S.; Free, P.; Hobley, J.; Fernig, D. G. Analyst 2014, 139, 4855-4861.

(10) Chen, H.; Huang, H.; Huang, X.; Clifford, J. N.; Forneli, A.; Palomares, E.; Zheng, X.; Zheng, L.; Wang, X.; Shen, P.; Zhao, B.; Tan, S. J. Phys. Chem. C 2010, 114, 3280-3286.

(11) Choi, H.; Raabe, I.; Kim, D.; Teocoli, F.; Kim, C.; Song, K.; Yum, J. H.; Ko, J.; Nazeeruddin, M. K.; Gratzel, M. Chem. - Eur. J. 2010, 16, 1193-1201.

(12) Evanoff, D. D.; Chumanov, G. J. Phys. Chem. B 2004, 108, 13957-13962.

(13) Félidj, N.; Aubard, J.; Lévi, G. J. Chem. Phys. 1999, 111, 1195-1208.

(14) Pelton, M.; Bryant, G. W. Introduction to Metal-Nanoparticle Plasmonics; Wiley: New York, 2013.

(15) Sokolov, S. V.; Eloul, S.; Katelhon, E.; Batchelor-McAuley, C.; Compton, R. G. Phys. Chem. Chem. Phys. 2017, 19, 28-43.

(16) Cheng, W.; Compton, R. G. TrAC, Trends Anal. Chem. 2014, 58, 79-89.

(17) Ellison, J.; Batchelor-McAuley, C.; Tschulik, K.; Compton, R. G. Sens. Actuators, B 2014, 200, 47-52.

(18) Lees, J. C.; Ellison, J.; Batchelor-McAuley, C.; Tschulik, K.; Damm, C.; Omanovic, D.; Compton, R. G. ChemPhysChem 2013, 14, 3895-3897.

(19) Bartlett, T. R.; Sokolov, S. V.; Plowman, B. J.; Young, N. P.; Compton, R. G. Nanoscale 2016, 8, 16177-16181.

(20) Jin, R.; Cao, Y.; Mirkin, C. A.; Kelly, K. L.; Schatz, G. C.; Zheng, J. G. Science 2001, 294, 1901-1903.

(21) Bohren, C. F.; Huffman, D. R. Absorption and scattering of light by small particles; Wiley: New York, 1983.

(22) Sheng, P. X.; Ting, Y. P.; Chen, J. P.; Hong, L. J. Colloid Interface Sci. 2004, 275, 131-141.

(23) Krause, K. J.; Brings, F.; Schnitker, J.; Katelhon, E.; Rinklin, P.; Mayer, D.; Compton, R. G.; Lemay, S. G.; Offenhausser, A.; Wolfrum, B. Chem. - Eur. J. 2017, 23, 4638-4643.

(24) Ellison, J.; Tschulik, K.; Stuart, E. J.; Jurkschat, K.; Omanovic, D.; Uhlemann, M.; Crossley, A.; Compton, R. G. ChemistryOpen 2013, 2, 69-75.

(25) Sokolov, S. V.; Tschulik, K.; Batchelor-McAuley, C.; Jurkschat, K.; Compton, R. G. Anal. Chem. 2015, 87, 10033-10039.

(26) Bartlett, T. R.; Sokolov, S. V.; Holter, J.; Young, N.; Compton, R. G. Chem. - Eur. J. 2016, $22,7408-7414$. 
(27) Alemán, J. V.; Chadwick, A. V.; He, J.; Hess, M.; Horie, K.; Jones, R. G.; Kratochvíl, P.; Meisel, I.; Mita, I.; Moad, G.; Penczek, S.; Stepto, R. F. T. Pure Appl. Chem. 2007, 79.

(28) Kourgiantakis, M.; Matzapetakis, M.; Raptopoulou, C. P.; Terzis, A.; Salifoglou, A. Inorg. Chim. Acta 2000, 297, 134-138.

(29) Arulmozhi, K. T.; Mythili, N. AIP Advances 2013, 3, 122122.

(30) Welcher, F. J. The Analytical Uses of Ethylenediamine Tetraacetic Acid; Van Nostrand, 1958.

(31) Park, J. W.; Shumaker-Parry, J. S. J. Am. Chem. Soc. 2014, 136, 1907-1921.

(32) Crea, F.; Falcone, G.; Foti, C.; Giuffrè, O.; Materazzi, S. New J. Chem. 2014, $38,3973$.

(33) Davies, C. W.; Hoyle, B. E. J. Chem. Soc. 1953, 4134.

(34) Bates, R. G.; Pinching, G. D. J. Am. Chem. Soc. 1949, 71, 1274-1283.

(35) Schubert, J. J. Am. Chem. Soc. 1954, 76, 3442-3444.

(36) Heinz, E. Biochem. Z. 1951, 321, 314.

(37) Meites, L. J. Am. Chem. Soc. 1951, 73, 3727-3731.

(38) Li, N. C.; Lindenbaum, A.; White, J. M. J. Inorg. Nucl. Chem. 1959, 12, 122-128.

(39) Korshunov, I. A.; P., P. A.; Tikhomirova, V. M. Zhur. neorg. Khim. 1957, 2, 68.

(40) Schubert, J.; Lind, E. L.; Westfall, W. M.; Pfleger, R.; Li, N. C. J. Am. Chem. Soc. 1958, 80, 4799-4802.

(41) Heitner, C.; Friedmann, D.; Goldschmidt, J. H.; Shamin, J. Bull. Soc. Chim. France 1958, 864.

(42) Migal, P. K.; Sycheu, A. Y. Zhur. neorg. Khim. 1958, 3, 314.

(43) Li, N. C.; Westfall, W. M.; Lindenbaum, A.; White, J. M.; Schubert, J. J. Am. Chem. Soc. 1957, 79, 5864-5870.

(44) Kety, S. S. J. Biol. Chem. 1942, 142, 181.

(45) Survila, A.; Mockus, Z.; Kanapeckait, S. Electrochim. Acta 2000, 46, 571-577.

(46) Tselesh, A. S. Thin Solid Films 2008, 516, 6253-6260.

(47) Lars Gunnar, S.; Arthur, M. E. Stability Constants of Metal-ion Complexes; London Chemical Society, 1964. 


\section{For TOC only}

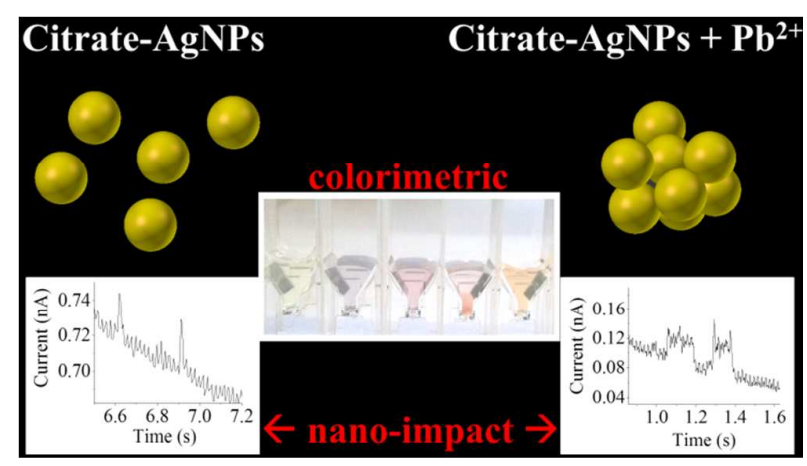

18

ACS Paragon Plus Environment 